\title{
Utilização de hortas escolares na promoção da educação alimentar com alunos do ensino fundamental
}

\author{
Use of school gardens to promote food education with elementary school
} students

Renata Fernandes de Matos

\begin{abstract}
Resumo: A utilização de hortas na educação alimentar é uma estratégia que possibilita agregar as informações teóricas repassadas pelos professores com os conhecimentos práticos desenvolvidos juntos aos alunos. Nesse contexto, diversos são os projetos possíveis de serem desenvolvidos para o trabalho da temática. Com o objetivo de investigar a eficiência da utilização de hortas no ensino da educação alimentar desenvolveu-se a presente pesquisa, tendo como foco escolas de ensino fundamental. Para isto, foram coletadas informações por meio da aplicação de questionários a alunos de duas escolas do município de Iguatu-CE, participantes de um projeto de extensão com hortas promovidos por alunos do curso de Licenciatura em Ciências Biológicas da UECE/FECLI. Em cada escola foram avaliadas duas turmas de sexto ano, totalizando 80 alunos participantes, contando para isto com a autorização dos pais, tendo em vista serem alunos menores de idade. Pelos resultados obtidos identificou-se que com a utilização de hortas nas aulas de educação alimentar os alunos puderam adquirir conhecimentos variados, pondo, a maioria destes, em prática a alimentação saudável. Os alunos realizam o consumo de hortaliças e reconhecem os benefícios destas, sendo os mesmos estimulados a instalarem hortas em suas próprias casas e a estenderem os conhecimentos adquiridos para o âmbito familiar. Assim, conclui-se que a utilização de hortas para o ensino da educação alimentar é uma prática viável e eficaz, resultando em benefícios para todos os envolvidos.
\end{abstract}

Palavras-chave: Alimentação saudável. Hortaliças. Mudança de hábitos.

Abstract: The use of vegetable gardens in food education is a strategy that allows the addition of theoretical information passed on by teachers with practical knowledge together with students. In this context, several projects are possible to be developed for the work of the theme. In order to investigate the efficiency of the use of vegetable gardens in the teaching of food education, develop a current research, focusing on elementary schools. To this end, information was collected on how to apply questionnaires to students from two schools in the municipality of Iguatu-CE, participating in an extension project with gardens promoted by students in the Biological Sciences course at UECE/FECLI. In each school, two sex classes were evaluated, totaling 80 participating students, with parental authorization, in view of students with a younger age. The results obtained identified that, with the use of vegetable gardens in food education classes, students were able to use varied knowledge, putting most of these in healthy eating practices. Students consume vegetables and recognize the benefits below, being encouraged to install gardens in their homes and a student with knowledge acquired for the family. Thus, it is concluded that the use of vegetable gardens for teaching food education is a viable and effective practice, resulting in benefits for all involved.

Keywords: Healthy eating. Vegetables. Changing habits. 


\section{Introdução}

A utilização de hortas no ambiente escolar é uma prática que vem auxiliando alunos e professores na construção do conhecimento. Diante da diversidade de temas que com estas podem ser trabalhados, um grande destaque se dá para a educação alimentar, a qual pode ser praticada associando as hortas com o processo de ensino-aprendizagem (MORGADO, 2006).

O cultivo de hortaliças nas escolas é uma ação que além de agregar conhecimentos, por meio da realização de atividades práticas, é favorável para uma mudança nos hábitos de vida de alunos e professores (SANTOS et al., 2014). Ao se ter uma horta disponível para a utilização em aulas, inúmeras são as possibilidades de se realizar tarefas relacionadas a promoção da saúde (CRIBB, 2010).

A educação alimentar tem composto o currículo escolar desde a década de 1990, onde, por meio dos Parâmetros Curriculares Nacionais, tem sido estabelecida como um tema transversal. Assim, com um aprendizado contínuo e permanente, propõem-se desenvolver nos alunos hábitos alimentares saudáveis, utilizando para isto recursos e abordagens educacionais ativas (BRASIL, 2012).

Nos últimos anos tem crescido o número de programas e projetos de educação alimentar implantados nas escolas, os quais têm apresentado como objetivo a conscientização e prevenção de doenças (BRASIL, 2012). Entre esses, ações desenvolvidas com hortas tem revelado benefícios relacionados a propagação do conhecimento, ajudando na melhoria da qualidade da merenda escolar (PIMENTA \& RODRIGUES, 2011) e reduzem os gastos com a compra de hortaliças (FIOROTTI et al., 2011).

Contudo, a educação alimentar é um tema complexo e que necessita de amplas abordagens (GREENWOOD, 2018). Conforme aponta Cotta e Machado (2013), os indivíduos enfrentam uma série de dificuldades ao buscar uma alimentação diversificada, nutritiva e saudável. Assim, faz-se necessário que desde cedo seja promovida uma conscientização e se estimule o consumo de hortaliças, impactando a família e a comunidade escolar (BRASIL, 2010). 
Nesse sentido, o conhecimento das hortaliças se configura como um ponto essencial para a prática de uma alimentação saudável, pois, uma vez que os alunos conseguem compreender seus benefícios, é possível inseri-las no consumo do dia a dia. Assim, uma serie de nutrientes poderá ser incorporada na dieta dos mesmos, destacando-se os carotenoides, antioxidantes e as fibras, o que promoverá, além da nutrição, o fortalecimento do sistema imunológico (WRIGHT et al., 2010).

Dessa forma, a promoção da educação alimentar, mediante o trabalho com hortas, vem se destacando na formação de alunos quanto a manutenção da boa alimentação (MONTEIRO \& COSTA, 2004). Logo, experiências podem ser extraídas dessa atividade e ações replicadas a fim de fortalecer o incentivo ao aprendizado e a melhoria da saúde e da qualidade de vida dos envolvidos (AMARAL, 2008).

Diante da relevância desse tema, a presente pesquisa tem por objetivo investigar a eficiência da utilização de hortas no ensino da educação alimentar em escolas de ensino fundamental.

\section{Metodologia}

A presente pesquisa apresenta viés qualitativo, o qual torna possível a análise estrutural dos fenômenos estudados e retrata as características do grupo de ínvidos analisado (SCHNEIDER et al., 2017). Por apresentar caráter exploratório, possibilita interpretar e compreender acontecimentos, fatos e pensamentos relacionados ao contexto investigado (GIL, 2008).

Sua realização se deu em duas escolas de ensino fundamental da cidade de Iguatu, a qual fica localizada na região Centro Sul do estado do Ceará. A mesma apresenta estimativa de 102.013 habitantes, com distância de $306 \mathrm{~km}$ da capital Fortaleza. No âmbito do ensino, a cidade é considerada referência, tanto no ensino básico como superior, reunindo instituições públicas e privadas.

Os participantes da pesquisa foram alunos do sexto ano do ensino fundamental. Estes fizeram parte de um projeto de extensão com hortas escolares desenvolvido por alunos do curso de Licenciatura em Ciências 
Biológicas da Universidade Estadual do Ceará/Faculdade de Educação, Ciências e Letras de Iguatu (UECE/FECLI).

Em cada escola existiam turmas de sexto ano funcionando no período da manhã e tarde, assim, considerando as quatro turmas avaliadas, pode-se coletar informações de 80 alunos. Para isto, foram aplicados questionários compostos por perguntas objetivas e subjetivas, os quais apresentaram perguntas em uma linguagem acessível ao entendimento dos alunos.

Nesse sentido, Moysés e Moori (2007) destacam que o questionário pode ser compreendido como um conjunto de perguntas apresentadas com o intuito de obter dados a fim de que os objetivos da pesquisa sejam alcançados. Para isto, o mesmo deve ser construído por perguntas ordenadas que devem ser respondidas por escrito sem a presença do entrevistador (MARCONI \& LAKATOS, 2015).

Para a análise dos dados, os resultados obtidos foram transformados em porcentagens e gráficos foram obtidos, utilizando-se para isto os recursos do programa Excel. Assim, pode-se dar uma maior visualização aos pontos em destaque na pesquisa, e, conforme propõe Minayo (2004), obter conclusões aproximadas da realidade dos entrevistados.

Todos os aspectos éticos e legais que regem a pesquisa foram obedecidos, estando a mesma em concordância com a lei 510/2016 do Conselho Nacional de Saúde (BRASIL, 2016). A mesma tem por objetivo evitar constrangimentos e prejuízos futuros aos participantes, garantindo todos os seus direitos, inclusive o anonimato. Para isto, os pais dos alunos assinaram um termo de assentimento, autorizando a utilização das informações coletadas, o que se deu uma vez que estes eram menores de idade.

\section{Resultados e discussão}

Com a utilização de hortas nas aulas de educação alimentar pode-se trabalhar com os alunos temas voltados para a alimentação saudável, tendo como objetivo realizar uma conscientização afim de estimula-los a consumir alimento benéficos à saúde. Com isto, procurou-se saber, na visão dos alunos, 
quais destes passaram a apresentar uma alimentação saudável após aprenderem sobre o assunto durante as aulas.

Como pode ser observado na Figura 1, dos alunos participantes da pesquisa, $85 \%$ indicaram que apresentam sim uma alimentação saudável. Isto é um ponto favorável, uma vez que estes puderam na prática entender o que configura uma boa alimentação, passando assim a adotar em casa hábitos muitas vezes não praticados anteriormente.

Figura 1- Alunos que consideram ter uma alimentação saudável

$85 \%$

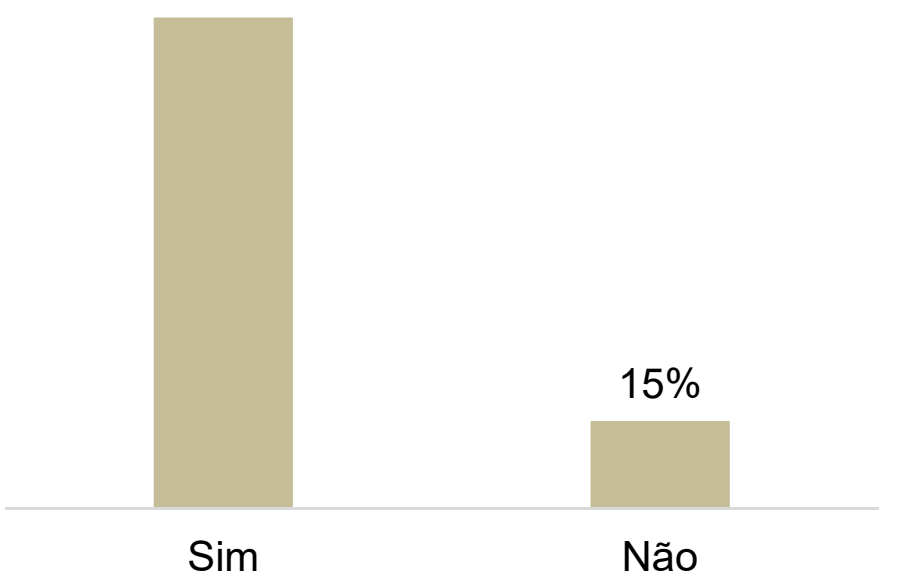

Porém, é necessário considerar que apesar de indicarem ter uma alimentação saudável, estes alunos ainda estão na educação básica, podendo não apresentar uma visão solidificada sobre o assunto, o que vai ser construído com o decorrer da formação e com as experiências obtidas. Contudo, destacase como positivo a visão atual, pois, demostra que os mesmos compreenderam a importância de se alimentar bem.

Nessa vertente, as escolas de educação básica no Brasil tornaram-se porta de entrada para ações relacionadas a alimentação, modificando não apenas o que os alunos conhecem por alimento, mas, sobretudo, contribuindo para o entendimento da relação destes com a saúde. Assim, os programas educacionais destacam-se como positivos para uma conscientização sobre a alimentação saudável (PRADO et al., 2016).

Entre os alunos entrevistados, $15 \%$ indicou não praticar uma alimentação saudável. Estes alunos, apesar de terem recebido os mesmos 
conhecimentos dos demais, acabaram não pondo em prática a mudança de hábitos. O que pode ser justificado pela faixa etária em que se encontram, uma vez que para crianças e adolescentes torna-se difícil a incorporação de alguns alimentos na dieta e a renúncia por outros.

Como o foco do projeto foi o ensino da educação alimentar com a utilização de hortas, perguntou-se aos alunos quantas vezes por semana estes realizavam o consumo de hortaliças. Conforme pode ser observado na Figura 2 , metade dos alunos entrevistados indicaram que realizam o consumo destes alimentos todos os dias da semana.

Figura 2- Número de vezes na semana em que os alunos consomem hortaliças

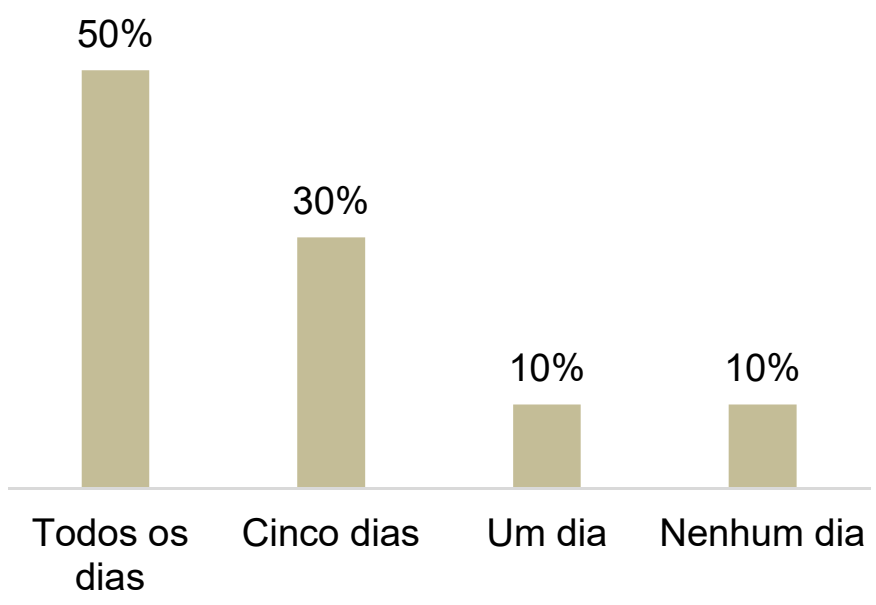

O consumo de hortaliças além de proporcionar uma série de benefícios para a saúde, ainda conta com a vantagem de ser um alimento de fácil aquisição e de baixo custo. Assim, é extremamente necessário que as hortaliças sejam incorporadas na alimentação diária, devendo-se atentar para a diversidade de cores e tipos, onde deve-se alternar entre suas partes comestíveis, como folhas, tubérculos, frutos e hastes, garantindo uma variação também nos nutrientes ingeridos.

Porém, não são todos os alunos que realizam este consumo diário, tendo $30 \%$ dos entrevistados indicado que as consomem cinco dias na semana. Contudo, este ainda é um consumo favorável, pois, mesmo que as hortaliças não sejam ingeridas todos os dias, ainda se observa uma boa nutrição para os alunos, uma vez que a nutrição pode ser considerada um ato 
involuntário, no qual os indivíduos ingerem alimentos benéficos para a sua saúde (RODRIGUES, 2009).

O que vem a ser preocupante é a indicação do restante dos alunos, dos quais, $10 \%$ afirmaram que consomem hortaliças apenas uma vez por semana e os outros $10 \%$ relataram que não consomem estes alimentos em nenhum dia da semana. O que indica serem estes os alunos de piores hábitos alimentares, confirmando o que foi discutido anteriormente, onde uma parcela dos entrevistados indicou não apresentar uma alimentação saudável.

Este fato pode ocorrer pela não preferência por este tipo de alimento, o que é apontado por Ferreira et al. (2007), os quais indicam que entre as principais causas da baixa seletividade de hortaliças por crianças e adolescentes destaca-se o sabor muitas vezes não palatável. Com isto, o seu consumo fica diretamente comprometido, uma vez que os alunos procuram evitar aquilo que segundo eles não gostam.

Somado a isto, observa-se um consumo frequente de produtos industrializados, estimulado pelas mudanças ocorridas na rotina ou na preferência de muitos alunos (COTA \& MIRANDA, 2006). Contudo, a falta de ingestão dos nutrientes oriundos dos produtos saudáveis pode acarretar sérios problemas aos indivíduos, o que se torna um fato agravante quando se trata de alunos em fase de crescimento.

Em vias de mudança dessa realidade, a escola assume um papel crucial, a qual, enquanto educadora, torna-se responsável pela inserção de novos hábitos na vida dos alunos. Uma vez que os alunos passam parte do seu dia no ambiente escolar, este torna-se um espaço favorável para práticas diferenciadas relacionadas a alimentação.

Para isto, tanto os professores como os demais profissionais que compõem a equipe escolar são responsáveis pelo uso de metodologias diferenciadas, a fim de promover a ampliação do conhecimento e a mudança dos hábitos de vida dos alunos (SILVA et al., 2013), o que é obtido com a execução de ações pedagógicas diferenciadas (BEZERRA; CAPUCHINO; PINHO, 2015). 
Assim, as hortas se destacam como uma das melhores estratégias, pois, além de todo o contexto teórico e prático possível de ser desenvolvido, os alunos ainda conseguem selecionar os alimentos que serão produzidos. Com isto, as hortaliças poderão ser inseridas na alimentação dos alunos na própria escola, fazendo parte principalmente da merenda escolar.

A inserção de hortaliças na alimentação de crianças e adolescentes deve ser feita de forma moderada, a fim de estimular um consumo por preferência e não por obrigação. Uma estratégia para isto é promover o consumo das hortaliças mais apreciadas. Com o objetivo de que estas fossem melhor conhecidas, pediu-se aos alunos que citassem suas hortaliças preferidas, possibilitando realizar o cultivo na horta e utilizá-las em explicações diversas durante e transmissão dos conhecimentos.

Na Figura 3 é possível observar as hortaliças citadas pelos alunos e a porcentagem de indicação de cada uma. Por estas citações observa-se uma diversidade de produtos, mostrando uma variabilidade na preferência pelas hortaliças, o que resulta em uma diversidade também de nutrientes, uma vez que hortaliças de coloração diferentes apresentam nutrientes diferentes, os quais são apontados de acordo com sua pigmentação (ALVARENGA, 2013).

Figura 3- Porcentagens de indicação das hortaliças preferidas pelos alunos

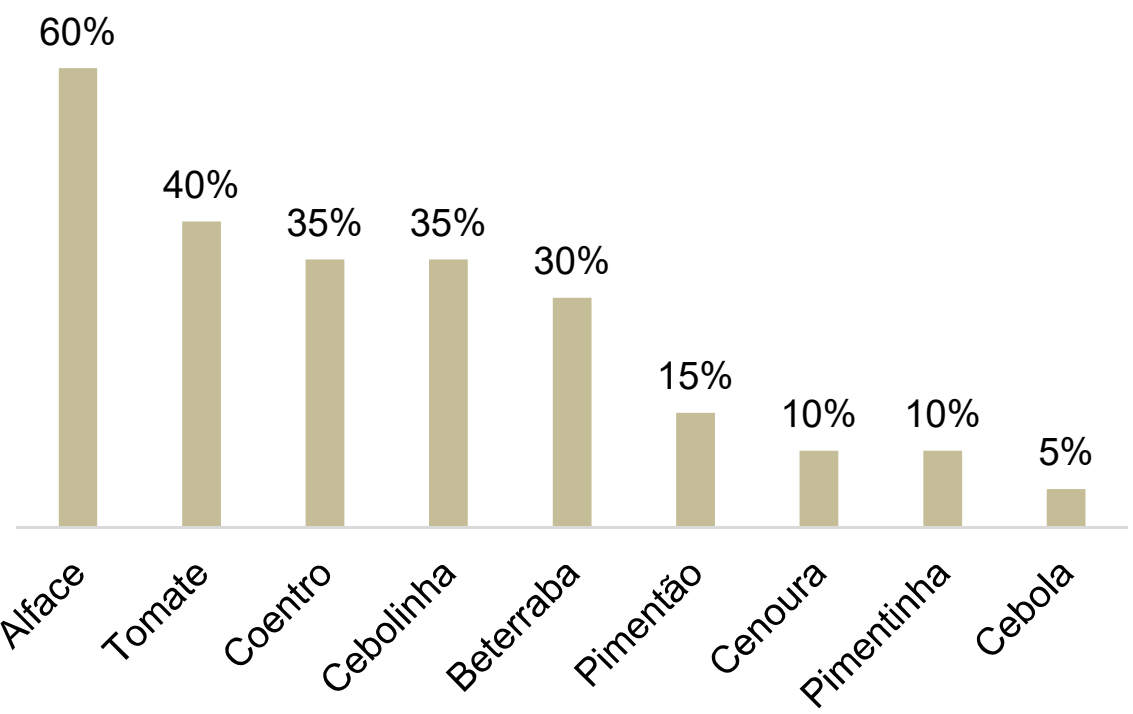

A hortaliça de maior preferência é o alface, o qual apresentou indicação por $60 \%$ dos alunos. Este pode ser utilizado em diversos tipos de salada, 
podendo para isto estar acompanhado de outras hortaliças ou não. Sua grande indicação é atribuída a popularidade na região, não apresentando gosto amargo ou intenso, o que aumenta seu consumo entre os alunos.

Algumas hortaliças apresentaram percentuais próximos de indicação, o que foi observado para tomate (40\%), coentro e cebolinha (35\% cada) e beterraba (30\%). Apesar da diversidade desses produtos, seu consumo não é tão expressivo, pois a indicação de cada um ocorreu por menos da metade dos alunos.

Entre essas hortaliças, coentro e cebolinha apresentaram o mesmo percentual de indicação por terem sido indicadas pelos mesmo alunos. Isto se dá pela tradição no consumo, onde, estes juntos compõe o que se conhece por "cheiro-verde". Contudo, também é comum encontrar relatos de que há uma maior preferência pelo coentro, pois a cebolinha apresenta uma ardência não palatável por muitos adolescentes.

Pimentão, cenoura, pimentinha e cebola foram as hortaliças menos indicadas, sobretudo a cebola, a qual apresentou indicação por apenas $5 \%$ dos alunos. Essa baixa porcentagem é atribuída ao mesmo fato comentado para a cebolinha, onde a ardência pode comprometer a preferência pelo seu consumo. Porém, o pimentão, mesmo apresentando ardência, contou com uma maior indicação, uma vez que o consumo dos pimentões coloridos se popularizou, apresentando estes pouca ardência.

O consumo estimulado dentro das casas dos alunos influenciou as indicações apontadas por estes, onde os mesmos citaram alimentos que já consumiram e que são comuns nas refeições em suas casas. Assim, a participação da família nas ações acerca da alimentação saudável implica nos hábitos dos alunos e também dos que com estes convivem (HERCULANO et al., 2010).

Com estes resultados foi possível nortear quais hortaliças que, ainda não estando sendo produzidas nas hortas das escolas, deveriam ser. Pesquisas dessa ordem são importantes por integrar os alunos no processo de construção do conhecimento, o que tende a facilitar a absorção de informações e a fortalecer a construção de uma aprendizagem significativa. 
$\mathrm{Na}$ educação alimentar, além de conhecer quais são os tipos de alimentos benéficos a saúde, é necessário também que os alunos conheçam o seu valor nutricional. Com isto, uma melhor seleção do que será consumido poderá ser feita, pois, em muitos casos os alunos optam por alimentos de baixo valor nutricional, ricos em gorduras e açúcares (FERNANDES et al., 2009).

Perguntou-se aos alunos se estes conheciam o valor nutricional dos alimentos, o que demostrou uma linha de trabalho amais a ser desenvolvida durante a realização do projeto. Isto se deu porque dos alunos entrevistado, $60 \%$ indicou não conhecer o valor nutricional de nenhum alimento, conforme pode ser observado na Figura 4.

Figura 4- Alimentos que os alunos conhecem o valor nutricional

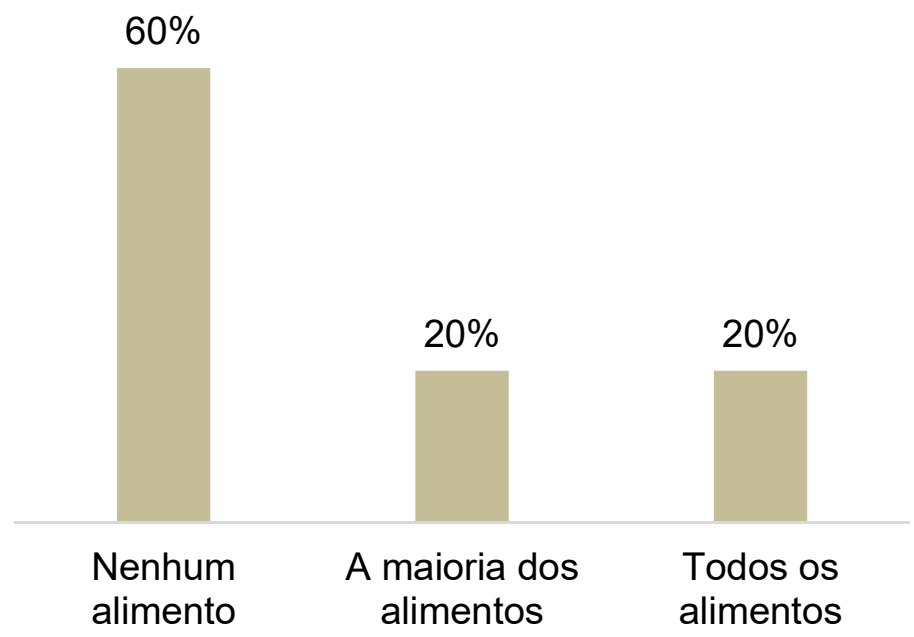

Por mais que o conhecimento do valor nutricional dos alimentos seja um assunto complexo, é necessário que desde as séries básicas este seja introduzido para os alunos. Assim, uma familiarização poderá ser promovida, estimulando os alunos a buscar mais informações e se aprofundarem no assunto, o que os fará valorizar ainda mais os alimentos benéficos à saúde, destacando-se nessa vertente as hortaliças.

A indicação de conhecimento do valor nutricional da maioria dos alimentos foi apontada por $20 \%$ dos entrevistados, porcentagem essa que se repetiu para o conhecimento do valor nutricional de todos os alimentos. Apesar dessas indicações serem favoráveis, destaca-se que foram baixas as suas porcentagens. 
Não conhecer o valor nutricional dos alimentos têm uma segunda implicação, onde, além da não valorização dos alimentos saudáveis, ainda pode-se realizar o consumo de alimentos com baixo valor nutricional pensandose serem estes bons para a saúde. A esta informação pode-se associar a preferência apesentada pelos alunos, para os quais alimentos como salgadinhos e doces muitas vezes substituem refeições que poderiam ser compostas por alimentos ricos em nutrientes como as frutas.

Ainda nessa vertente, os alunos foram indagados quanto aos componentes dos alimentos. Pela Figura 5, observa-se que os compostos mais conhecidos pelos alunos são as vitaminas, o que foi indicado por $90 \%$ dos alunos. Isto pode ter se dado pelo enfoque durante as aulas de educação alimentar com o uso das hortas, uma vez que as hortaliças são alimentos ricos em vitaminas (WRIGHT et al., 2010).

Figura 5- Porcentagens de indicação dos compostos conhecidos pelos alunos

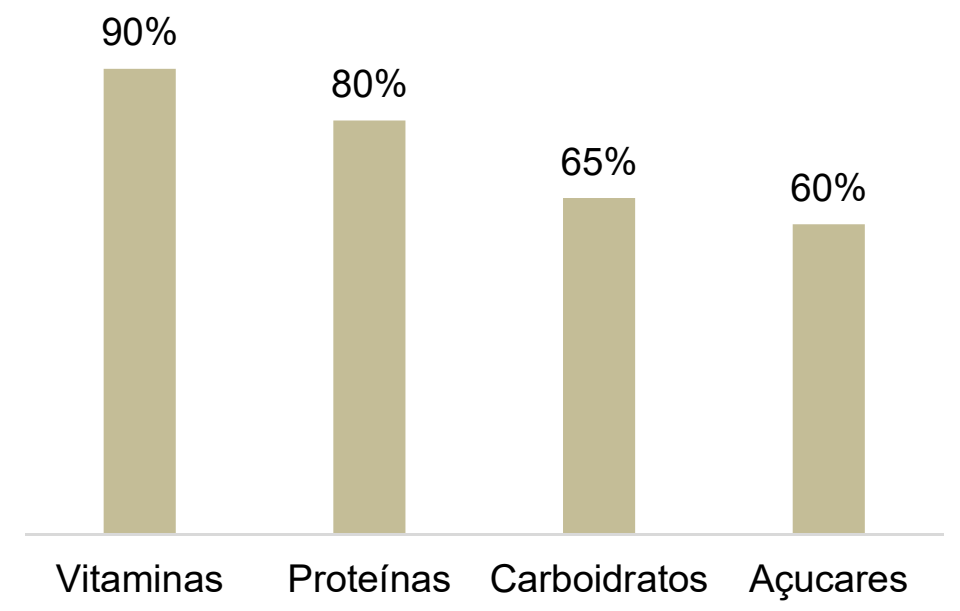

Isto mostra a viabilidade do desenvolvimento de projetos que incentivam o conhecimento sobre as boas práticas alimentares em associação com o cultivo de hortaliças, o que conduz a mudança nos hábitos de vida não apenas dos alunos, mas também de professores (SANTOS, 2014). Isto ocorre porque, ao transmitirem o conhecimento, os professores realizam uma reciclagem do assunto, contando com o desafio de terem que incentivar seus alunos a colocar em prática o que estão aprendendo.

As proteínas também apresentaram elevada indicação, dando-se esta por $80 \%$ dos alunos. Um destaque deve ser dado a tais compostos por serem 
utilizados como percussores para as mais diversas reações no organismo humano. Assim, quando os alunos indicam conhecê-los, entende-se que o ensino com a utilização das hortas foi eficiente, uma vez que alguns alimentos vegetais apresentam quantidades de proteína que podem se igualar aos alimentos de origem animal.

Os compostos que apresentaram menores indicações foram os carboidratos, com $65 \%$ de indicação, e os açucares, com $60 \%$. Estes, apesar de fazerem parte da composição dos alimentos não são benéficos a saúde, por mais que sejam necessários em quantidades moderadas. Isto pode ter sido o motivo do baixo conhecimento pelos alunos, uma vez que nas aulas são focados os compostos que enriquecem nutricionalmente os alimentos. Assim, entende-se que os alunos que afirmaram ter uma alimentação saudável, realmente apresentam uma seletividade quanto ao que consomem.

Tais compostos são facilmente encontrados nas embalagens dos produtos industrializados, contudo, para as hortaliças, estas informações nem sempre estão disponíveis. O que se observa quando estas são adquiridas em mercados ou feiras livres, pois, nem sempre as embalagens contam com uma seção informativa.

Assim, as escolas se tornam ainda mais responsáveis pela passagem dessas informações, as quais, após obtidas se somam as experiências vivenciadas no dia a dia dos alunos. Nesse contexto, Aquilla (2011) enfatiza que é necessário a incorporação dos saberes informais ao estudo da educação alimentar, contribuindo para sua solidificação.

Apesar da eficácia na utilização de hortas para o ensino da educação alimentar, o que é aprendido no ambiente escolar deve ser levado pelos alunos para suas casas e lá posto em prática. Assim, com o trabalho desses temas espera-se que o consumo das hortaliças passe a ser uma prática constante pelos alunos, sendo um ponto chave para isto a existência de hortas nas suas próprias residências.

Com a visão de instrui-los a instalarem hortas em suas casas, inicialmente fez-se o levantamento de quais alunos já contam com esse recurso em suas residências. Pelos dados da Figura 6, observa-se que é baixo 
o percentual de alunos que contam com a produção doméstica de hortaliças, o que foi apontado por apenas $15 \%$ dos entrevistados.

Figura 6- Alunos que tem hortas instaladas em suas casas

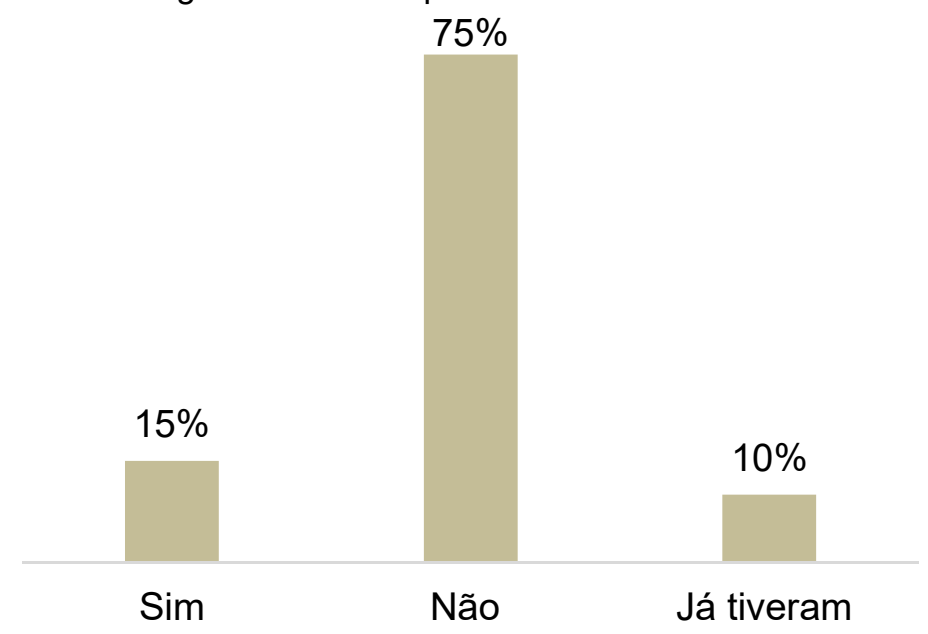

Esses alunos podem, de uma forma mais concreta, continuar a praticar o que aprenderam durante o projeto. Por terem hortaliças sendo produzidas em suas casas, o consumo constante pode ser facilitado, pois, o hábito de colher leva ao hábito de plantar novamente. Assim, diariamente pode-se ter um enriquecimento nutricional das refeições.

Um percentual de $75 \%$ dos alunos indicou não haver hortas em suas casas. Para estes, o consumo de hortaliças encontra-se condicionado a sua compra, uma vez que nem culturas básicas como o coentro e a cebolinha são produzidas em seus lares. Com isto, a prática de uma alimentação saudável torna-se ainda mais difícil, sendo interessante realizar cultivos nem que sejam improvisados, já que atualmente tem-se um grande sucesso na construção de hortas em pequenos espaços.

Os $10 \%$ restante afirmaram que em suas casas atualmente não tem hortas instaladas, mas que em algum momento estas já estiveram presentes, onde a prática de cultivar hortaliças já foi realizada. Contudo, é importante que ocorra um resgate dessa atividade, o que vai se somar os conhecimentos que agora os alunos apresentam, tanto em relação a horta como em relação a alimentação saudável. 
Uma vez que são poucos os alunos que apresentam hortas em suas casas, os conhecimentos adquiridos poderão servir para dar início a uma nova atividade, ou mesmo resgatá-la. A utilização das hortas para o ensino da educação alimentar vai assim além da transmissão do conhecimento, podendo a vivência da atividade, em todo o seu contexto, estender-se do âmbito escolar para o familiar, havendo ainda muito o que ser explorado nesse campo.

\section{Considerações finais}

Com a realização dessa pesquisa fica claro que a utilização de hortas em aulas de educação alimentar é uma atividade viável e eficaz no ensino fundamental. Com estas, os alunos são conduzidos a aquisição de conhecimentos e a vivência prática de atividades que modificam sua percepção quanto aos alimentos e quanto a sua forma de produção e consumo.

A diversidade de estratégias utilizadas na abordagem do assunto é um desafio que deve ser vivenciado tanto pelos professores como por toda a comunidade escolar. Dessa forma, de uma maneira integralizada, os benefícios poderão ser observados no crescimento profissional e pessoal de todos os envolvidos, o que inclui as famílias dos alunos para as quais estes levarão seus conhecimentos.

\section{Referências}

ALVARENGA, D. F. F. Hortaliças. Cartilha publicada pelo Departamento Técnico EMATER-MG, 2013.

AMARAL, C. M. C. Educação alimentar. FMPB, 2008. Disponível em: www.fmpb.org.br/mostraconteudos.asp?cod_conteudo>. Acesso em: 20 Jan. 2020.

AQUILLA, R. A educação alimentar e nutricional no espaço escolar: saber, sabor e saúde. 2011. Dissertação. Mestrado em Educação nas Ciências. Universidade Regional do Noroeste. ljuí-RS, 2011. Disponível em: $<$ https://bibliodigital.unijui.edu.br:8443/xmlui/bitstream/handle/123456789/284/R OSEMERI\%20AQUILLA.pdf?sequence=1>. Acesso em: 28 Abr. 2020.

BEZERRA, K. F.; CAPUCHINHO, L. C. F. M.; PINHO, L. Conhecimento e abordagem sobre alimentação saudável por professores do ensino fundamental. Demetria, v. 10, n. 1, p. 119-131, 2015. 
BRASIL. Programa Mais Educação. Decreto $n^{\circ} 7.083$ de 27 de janeiro de 2010. Brasília-DF, 2010.

Marco de referência de educação alimentar e nutricional para as políticas públicas. Secretaria Nacional de Segurança Alimentar e Nutricional. Brasília-DF, 2012.

Conselho Nacional de Saúde. Lei $n^{\circ} 510$ de 07 de abril de 2016. Presidência da República Casa Civil.

COTA, R. P.; MIRANDA, L. S. Associação entre constipação intestinal e estilo de vida em estudantes universitários. Revista Brasileira de Nutrição Clínica. v. 21, n. 4, p. 296-301, 2006.

COTTA, R. M. M.; MACHADO, J. C. Programa Bolsa Família e segurança alimentar e nutricional no Brasil: revisão crítica de literatura. Panam Salud Publica, v. 33, n. 1, p. 54-60, 2013.

CRIBB, S. L. S. P. Contribuições da educação ambiental e horta escolar na promoção de melhorias ao ensino, à saúde e ao ambiente. Ensino, Saúde e Ambiente, v. 3, n. 1, p. 42-60, 2010.

FERNANDES, P. S. Evaluating the effect of nutritional education on the prevalence of overweight/obesity and on foods eaten at primary schools. Jornal de Pediatria, v. 21, n. 4, p. 1-10, 2009.

FERREIRA, A. F.; CHIARA, V. L.; KUSCHNIR, M. C. C. Alimentação saudável na adolescência: consumo de frutas e hortaliças entre adolescentes brasileiros. Adolescência \& Saúde. v. 4, n. 2, p. 48-52, 2007.

FIOROTTI, J. L; CARVALHO, E. S. S.; PIMENTEL, A. F.; SILVA, K. R. Horta: a importância no desenvolvimento escolar. Anais, XIV Encontro LatinoAmericano de Iniciação Científica. Universidade Vale do Paraíba, 2011. Disponível em: <www.inicepg.univap.br/cd/INIC_2010/anais/arquivos/0566_0332_01.pdf>. Acesso em: 14 Fev. 2020.

GIL, A. C. Métodos e técnicas de pesquisa social. 6. ed. Editora Atlas SA, 2008.

GREENWOOD, S. A. Educação alimentar e nutricional e o livro didático: caminhos percorridos e objetivos perseguidos. 2014. Dissertação (Mestrado em Educação em Ciências e Saúde) - Núcleo de Tecnologia Educacional Para a Saúde, Universidade Federal do Rio de Janeiro, Rio de Janeiro, 2014.

Disponível

em:

<http://ptdocz.com/doc/126402/educa\%C3\%A7\%C3\%A3o-alimentar-enutricional-e-o-livro-did\%C3\%A1tico->. Acesso em: 18 Fev. 2020.

HERCULANO, T. B.; CARNEIRO, A. D.; ALENCAR, A. S.; OLIVEIRA, B. M.; SOUZA, M. P. M.; FARIAS, J. A.; SOUSA, C. S. M. Alimentação saudável: o papel da escola na construção de novos hábitos. In: Encontro latino 
americano de iniciação científica. Univap, p. 1-4. 2010, Disponível em: <http://www.inicepg.univap.br/cd/INIC_2010/anais/arquivos/0582_0698_01.pdf> . Acesso em: 25 Mar, 2020.

MARCONI, M. A.; LAKATOS, E. M. Fundamentos de metodologia científica. 8. ed. São Paulo, Atlas, 2015.

MINAYO, M. C. S. O desafio do conhecimento: pesquisa qualitativa em saúde. São Paulo. 8. ed. Hucitec, 406 p. 2004.

MONTEIRO, P. H. N., COSTA, R. B. L. Alimentação saudável e Escolas: possibilidades e incoerências. In: Qualidade de vida - Boletim do Instituto de Saúde. P. 22. No 32, Abril 2004. Disponível em: <www.isaude.sp.gov.br>. Acesso em: 18 Abr. 2020.

MORGADO, F. S.; SANTOS, M. A. A. A Horta Escolar na Educação Ambiental e Alimentar: Experiência do Projeto Horta Viva nas Escolas Municipais de Florianópolis. Revista Eletrônica de Extensão, v. 5, n. 6, p. 1-10, 2008.

MOYSÉS, G. L. R; MOORI, R. G. Coleta de dados para a pesquisa acadêmica: um estudo sobre a elaboração, a validação e a aplicação eletrônica de questionário. In: encontro nacional de engenharia de produção, 2007, Foz do Iguaçu. Anais... Abepro, 2007, p. 1-10. Disponível em: <http://abepro.org.br/biblioteca/ENEGEP2007_TR660483_9457.pdf>. Acesso em: 25 Mar. 2020.

PIMENTA, J. C.; RODRIGUES, K. S. M. Projeto Horta Escola: ações de educação ambiental na escola centro promocional todos os santos de Goiânia (GO). Simpósio de educação ambiental e transdisciplinaridade, v. 2, p. 8-9, 2011. Disponível em: <https://files.cercomp.ufg.br/weby/up/52/o/29_Horta_na_escola.pdf>. Acesso em: 22 Jan. 2020.

PRADO, B. G.; FORTES, E. N. S.; LOPES, M. A. L.; GUIMARÃES, L. V. Ações de educação alimentar e nutricional para escolares: um relato de experiência. Demetra, v. 11, n. 2, p. 369-382, 2016.

RODRIGUES, M. L. C. Alimentação e nutrição no Brasil. Brasília: Universidade de Brasília, 2009. Disponível em: <http://portal.mec.gov.br/seb/arquivos/pdf/profunc/aliment.pdf>. Acesso em: 14 Abr. 2020.

SANTOS, M. J. D.; AZEVEDO, T. A. O.; FREIRI, J. L. O.; ARNAUD, D. K. L.; REIS, F. L. A. M. Horta Escolar Agroecológica: Incentivadora da aprendizagem e de mudanças de hábitos alimentares no Ensino Fundamental. Holos, v. 4, n. 30, p. 278-290, 2014.

SCHNEIDER, E. M; FUJII, R. A. X; CORAZZA, M. J. Pesquisas qualiquantitativas: contribuições para a pesquisa em ensino de ciências. Revista Pesquisa Qualitativa, v. 5, n. 9, p. 569-584, 2017. 
SILVA, M. X.; SCHWENGBER, P.; PIERUCCI, A. P. T. R.; PEDROSA, C. Abordagem lúdico-didática melhora os parâmetros de educação nutricional em alunos do ensino fundamental. Ciências \& Cognição, v. 18, n. 2, p. 136-148, 2013.

WRIGHT, J. Terapia cognitivo-comportamental para doenças mentais graves. Porto Alegre: Artmed, 2010.

\section{Sobre os Autores}

\section{Renata Fernandes de Matos}

renatafmatos@hotmail.com

É professora do Curso de Ciências Biológicas da UECE/FECLI, atuando no setor de Genética e Evolução. Engenheira Agrônoma pela Universidade Federal do Ceará, Campus Cariri (2013). Mestre em Agronomia/Fitotecnia com ênfase em Genética e Melhoramento de Plantas, pela Universidade Federal do Ceará (2016). Doutoranda em Agronomia/Fitotecnia com ênfase em Genética e Melhoramento de Plantas, pela Universidade Federal do Ceará. Participou do Grupo de Pesquisa e Extensão em Agroecologia (GPEA) e do Núcleo de Estudo em Fitotecnia e Melhoramento de Plantas (NEFIMP) 